\title{
Effect of thermoplastic filling techniques on the push-out strength of root sealing materials
}

Zigomar Hideo Fecchio Nasser HORIUCHI(a)

Yara Teresinha Correa

SILVA-SOUSA(a)

Walter RAUCCI-NETO(a)

Fuad Jacob Abi RACHED-JUNIOR ${ }^{(a)}$

Aline Evangelista SOUZA-GABRIEL ${ }^{(b)}$

Silvio Rocha Corrêa da SILVA(a)

Edson ALFREDO (a)

(a) Universidade de Ribeirão Preto - UNAERP, School of Dentistry, Dentistry Department, Ribeirão Preto, SP, Brazil.

(b) Universidade de São Paulo - USP, School of Dentistry of Ribeirão Preto, Department of Restorative Dentistry, Ribeirão Preto, SP, Brazil.

Declaration of Interests: The authors certify that they have no commercial or associative interest that represents a conflict of interest in connection with the manuscript.

Corresponding Author:

Walter Raucci-Neto

E-mail: rauccineto@yahoo.com.br

DOI: 10.1590/1807-3107BOR-2016.vol30.0001

Submitted: Apr 23, 2015

Accepted for publication: Jul 06, 2015

Last revision: Sep 03, 2015
Abstract: This study evaluates the effect of two thermoplastic obturation systems (MicroSeal and Obtura II) on bond strength of different sealers to intraradicular dentin. Sixty root canals of human canines were prepared using ProTaper rotary files (crown-down technique) and irrigated with $2.5 \%$ sodium hypochlorite and $17 \%$ EDTA. The root canals were filled by MicroSeal, Obtura II, or lateral compaction techniques using AH Plus and Epiphany SE. $1.5 \mathrm{~mm}$ thick root slices were subjected to the push-out test. ANOVA and Tukey's test showed that the bond strength values (MPa) observed in the groups obturated with MicroSeal $(2.96 \pm 2.72)$ and Obtura II $(2.68 \pm 2.18)$ did not significantly differ from each other $(p>0.05)$ but were significantly higher than that observed in the group obturated with lateral condensation $(2.01 \pm 1.48 ; \mathrm{p}<0.05)$. There were no statistically significant differences in strength $(p>0.05)$ among the root canal thirds (cervical: $2.44 \pm 2.03$; middle: $2.50 \pm 2.27$; and apical: $2.70 \pm 2.34)$. Adhesive failures were predominant $(60 \%)$ in all groups. In conclusion, MicroSeal and Obtura II techniques, using AH plus sealer, increased the resistance to displacement of the filling material, when compared with lateral compaction. Moreover, when used with Epiphany SE, these obturation systems did not affect the bond strength of the material to root dentin.

Keywords: Endodontics; Dental Bonding; Root Canal Obturation.

\section{Introduction}

Several reports have shown that incomplete apical and coronal three-dimensional fluid-tight seals are the main cause of endodontic treatment failure. ${ }^{1,2,3,4}$ According to De-Deus et al. ${ }^{5}$ and Gulsahi et al., ${ }^{6}$ the material should completely fill the root canal, and the ideal outcome is a high volume of core material, generally gutta-percha, and a small quantity of sealer, to prevent growth of residual bacteria and inhibit introduction of new bacteria.

Different filling techniques have been proposed in an attempt to obtain compact sealing properties. ${ }^{78,9,10,11}$ Among these techniques, lateral-compaction with gutta-percha points provides adequate apical sealing. However, the efficiency of the technique mainly depends on the type of sealer used..$^{1}$ Therefore, thermoplastic canal filling methods are indicated to allow condensation of warm gutta-percha in all the root 
canal irregularities. ${ }^{9}$ Moreover, these techniques allow correction of failures during the filling process without requiring complete removal of material.,3,12

The MicroSeal (AnalyticEndodontics/Kerr, Orange, USA) is a thermomechanical filling technique that comprises placement of a laterally compacted master gutta-percha cone and additional gutta-percha to backfill the canal. Modifications of this technique have been proposed to enable filling of root canals with complex anatomy. These include use of accessory gutta-percha points and vertical compaction with a plugger to increase adaptation of the gutta-percha to the root canal.,33

The efficiency of injectable, thermoplasticized gutta-percha in filling canal irregularities has already been recognized. ${ }^{14}$ Placement of a master gutta-percha cone in the apical part of the root canal prior to injection has been suggested to prevent overfilling and apical extrusion. ${ }^{15,16}$ The core-carrier technique, which uses heat-softened alpha phase gutta-percha encased in a plastic carrier, provides excellent adaptation of the material to the prepared canal walls and irregularities. ${ }^{17}$ It is recommended that lateral-compaction be performed using ultrasonically energized spreaders producing frictional heat and plasticized gutta-percha to produce a homogeneous root filling. ${ }^{14}$

Various obturation techniques present with various distinctive features; therefore, the null hypothesis of this study was to compare the push out bond strengths of MicroSeal and Obtura II (Obtura Corporation, Fenton, USA) obturation techniques using epoxy-based (AH Plus) and methacrylate-based (Epiphany) sealers.

\section{Methodology}

This study was approved by the Ethical Committee of Universidade de Ribeirão Preto - UNAERP, SP, Brazil (protocol 071/09).

Maxillary human canines stored in $0.1 \%$ thymol solution were washed in running water for $24 \mathrm{~h}$ to eliminate residues, and sixty teeth were selected on the basis of their roots, which should be completely formed, present a single canal without calcifications or accentuated curvature. The crowns were removed at the cementoenamel junction with a water-cooled diamond disk (KG-Soresen, Barueri, Brazil), and the roots were trimmed coronally to a uniform length of 18 mm. A \#10K-file (Dentsply-Maillefer, Ballaigues,
Switzerland) was passively introduced into each root canal to confirm the working length $(17 \mathrm{~mm})$. Teeth with laterally displaced foramina and/or canal length less than $17 \mathrm{~mm}$ were replaced.

The canals were instrumented with the ProTaper-Universal (Dentsply-Maillefer, Ballaigues, Switzerland). The cervical-third was prepared with the instrument SX and the middle and apical-thirds were prepared with the instruments S1, S2, F1, F2, F3, F4 and F5 that were attached to the handpiece of a rotary system activated by an electric engine (Endo-Plus-VK-Driller, São Paulo, Brazil). The canals were irrigated with $2 \mathrm{~mL}$ of $2.5 \% \mathrm{NaOCl}$ at each file change using NaviTip needles coupled to plastic syringes (Ultradent-Products Inc., South Jordan, USA). As final flush 17\% EDTA (Farmácia de manipulação da Terra, Ribeirão Preto, Brazil) was used for $3 \mathrm{~min}$, followed by flushing with $10 \mathrm{~mL}$ of distilled water and dried with absorbent paper points (Tanari-Tanariman Industrial Ltda., Manacapuru, Brazil).

The root canals were separated according to the following groups $(n=20)$ : lateral-compaction; Obtura II and MicroSeal. Each group was divide into 2 subgroups, according to the sealer used: Epiphany SE (Pentron-Clinical-Technologies, LLC, Wallingford, USA) a methacrylate resin-based sealer and AH Plus (De Trey-Dentsply, Konstanz, Alemanha) an epoxy resin-based sealer.

Both sealers were manipulated according to the manufactures instructions and inserted into root canal with a lentulo spiral attached to a low-speed handpiece (Dabi-Atlante, Ribeirão Preto, Brazil) to avoid bubble formation.

Lateral-compaction: after a \#50 gutta-percha cone (Dentsply-Herpo, Petrópolis, Brazil) was fitted to the working length, cold lateral-compaction was performed using a nickel-titanium finger spreader, (Hyflex, size medium, Hygenic Corporation, Akron, USA) and matching accessory gutta-percha cones (Dentsply-Herpo, Petrópolis, Brazil), beginning from the lingual part of the canal and then continued around the canal periphery until the spreader could only penetrate $2-3 \mathrm{~mm}$ into the canal. Approximately 16-20 accessory gutta-percha cones were used in each canal. A heated instrument was used to sear off and vertically compacted the extended ends of the cones. 
Obtura II: a plugger that penetrates $3 \mathrm{~mm}$ short of the working length was used for binding point. After sealer insertion, the \#50 master cone was placed into the canal and the heated plugger maintained only the apical gutta-percha. Backfill of the canal was accomplished using warm gutta-percha injection. Obtura II was set at $200^{\circ} \mathrm{C}$ and the needle placed into the root canal against the apical gutta-percha for $5 \mathrm{~s}$ before extruding the gutta-percha. The mass of gutta-percha forced the needle coronally to the canal orifice. A plugger was used to compact the gutta-percha at the orifice level.

MicroSeal: after sealer insertion, the master cone (MicroFlow \#50) was coated with sealer and inserted into the root canal. A. 04 taper MicroSeal-Spreader (Analytic-Endodontics, Glendora, USA) was seated alongside the master cone and the MicroFlow-Cartridge containing ultra-low fusing gutta-percha was attached to MicroFlow-Syringe and inserted into a MicroSeal-Heater at $90^{\circ} \mathrm{C}$ for $45 \mathrm{~s}$. The MicroFlow-Syringe was removed from the heater and a. 04 taper condenser was coated with plasticized gutta-percha by inserting into the syringe and applying steady pressure as the condenser was withdraw from the syringe. The condenser was rotated at $5000 \mathrm{rpm}$ for $10 \mathrm{~s}$ to insure the complete filling of plasticized gutta-percha into the canal. A plugger was used to compact the gutta-percha at the orifice level.

For Epiphany SE subgroups, the sealer photoactivation was performed for $40 \mathrm{~s}$ with the light (Ultralux, Dabi-Atlante, Ribeirão Preto, Brazil) pointed to the cervical root-third. The photoactivator was fixed in a dispositive that standardize the focal distance in $10 \mathrm{~mm}$.

After the root canal filling procedure the cervical opening was sealed with a temporary restorative material (Coltosol,Vigodent, Rio de Janeiro, Brazil) and were placed immediately at $37^{\circ} \mathrm{C}$ and $95 \%$ humidity for a period three times greater than the regular setting time of the sealer (135 min for AH Plus and $45 \mathrm{~min}$ for Epiphany SE) before the bond strength test.

The push-out test was performed as described by Gonçalves et al..$^{18}$ The roots were fixed on acrylic plates using wax (Kota-Import, São Paulo, SP, Brazil) and sectioned in a precision cutting machine (Minitom-Struers, Westlake, USA) at $375 \mathrm{rpm}$. Nine
$1.5 \mathrm{~mm}$ thick slices were obtained from each root (3 per root-third), resulting in a total of 540 specimens.

The first slice of each third was selected and a stainless steel support was used to hold the specimens in an Instron 4444 universal testing machine (Instron-Corporation, Canton, USA) in such a way that the side with the smaller diameter of the root canal faced upwards and was aligned to the shaft that would exert pressure load on the sealer (apical-coronally) until debonding occurred. A $6 \mathrm{~mm}$ long shafts with tip diameter of $0.6 \mathrm{~mm}$ for the apical-third and $1 \mathrm{~mm}$ for the coronal and middle-thirds were used. This method assured the alignment of the specimen in an accurate and reproducible manner and also maintained the shaft centralized to avoid its contact with the dentin during testing. The force needed to dislodge the filling material ( $\mathrm{F}$ in $\mathrm{kN}$ ) was transformed into tension ( $\sigma$ in $\mathrm{MPa}$ ) by dividing the force by the adhesive area of the filling material (SL in $\mathrm{mm}^{2}$ ), using the following equation:

$$
\sigma=F / A
$$

After push-out test, the slices were examined with a stereomicroscope (ZEISS, Stemi 2000-C, Oberkochen, Germany) at $325 \times$ to determine the failure pattern. Failure was considered adhesive if the sealer was totally separated from dentin (dentin surface without sealer), cohesive if the fracture occurred within the sealer (dentin surface totally covered by the sealer), and mixed when a mixture of adhesive and cohesive modes (dentin surface partially covered by the sealer) occurred (Figure). ${ }^{18}$

Mean values were statistically compared. The Kolmogorov-Smirnov test showed that the results were consistent with a normal distribution curve. Parametric statistical analysis was performed (ANOVA and post hoc Tukey test). The significance level was set as 5\% (SPSS 17.0; SPSS Inc., Chicago, USA).

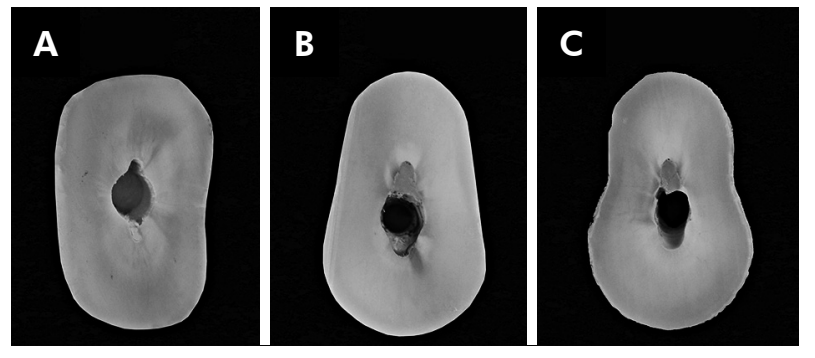

Figure. Example photographs of the failures: (A) adhesive failure, (B) cohesive failure, (C) mixed failure. 


\section{Results}

The mean and standard deviations of the bond strength values (in $\mathrm{MPa}$ ) for the displacement of the filling materials during the push-out test are presented in Table 1.

Obtura II and MicroSeal presented the highest values for material displacement $(2.68 \pm 2.18$ and $2.96 \pm 2.72 \mathrm{MPa}$, respectively) and exhibited similar statistical significance $(\mathrm{p}>0.05)$. Lateral-compaction presented the lowest values for material displacement $(2.01 \pm 1.48 \mathrm{MPa})$ and was statically different from the thermoplastic techniques ( $p<0.05)$.

Regardless of the filling technique used, $\mathrm{AH}$ Plus presented higher push-out bond strength values $(4.34 \pm 1.80 \mathrm{MPa})$ than Epiphany SE $(0.75 \pm 0.27 \mathrm{MPa} ; \mathrm{p}<0.05)$.

Analysis of the interaction between filling technique and sealer showed that Obtura II and MicroSeal filled with AH Plus presented the highest adhesion values $(4.46 \pm 1.48$ and $5.16 \pm 2.22 \mathrm{MPa}$, respectively) and lateral-compaction filled with Epiphany SE presented the lowest adhesion values $(0.72 \pm 0.23 \mathrm{MPa} ; \mathrm{p}<0.05)$. On using Epiphany SE, no statistically significant difference $(p>0.05)$ was observed between the filling techniques; in addition, it also presented the lowest adhesion values.

There were no statistically significant differences ( $p>0.05$ ) between the root-thirds (cervical: $2.44 \pm 2.03$, middle: $2.50 \pm 2.27$, and apical: $2.70 \pm 2.34 \mathrm{MPa}$ ).

Analysis of the mode of failure showed a predominance of adhesive failures $(60 \%)$ in all groups, particularly at the sealer/dentin interface. There were a many mixed failures in the specimens filled with AH Plus compared with those with Epiphany SE. Cohesive failures were observed in $17 \%$ of the specimens filled with Obtura II and AH Plus. The distribution of failure modes is presented in Table 2.

\section{Discussion}

The selection and use of appropriate filling techniques is essential to completely fill the root canal and prevent bacterial infection, the main cause of apical periodontitis. The quality of root canal fillings is generally evaluated using two-dimensional radiographs, ${ }^{19}$ leakage models ${ }^{1,5}$ and cross-sectional methods., ${ }^{3,12}$ These techniques enable visualization of the distribution of root filling materials, such as gutta-percha and sealer, inside the canal. ${ }^{3}$ However, the sealer bond strength is related to its ability to remain adhered to the root dentin walls,$^{20}$ and this property is important in static and dynamic situations. In static circumstances, the adhesion eliminates spaces that allow infiltration of fluids into the sealer/dentin interface. In dynamic situations, the adhesion is necessary to prevent sealer dislodgment during prosthetic procedures. ${ }^{21}$ The push-out test has been shown to be effective and reliable in the assessment of sealers bond strength to dentin, as it evaluate the material dislocation resistance. ${ }^{22}$ Furthermore, the pushout test causes failure parallel to the dentin/material interface, which is similar to that observed in clinical circumstances. ${ }^{23,24}$ In this study, the push-out test was used to compare the bond strength of two different thermoplastic filling techniques using epoxy- and methacrylate-based sealers. Differences in bond strength were observed between the techniques as well as the sealer types used, thereby rejecting the null hypothesis.

The findings of this study showed that, regardless of the filling technique used, AH Plus presented higher push-out bond strength values than Epiphany SE. According to Carneiro et al., ${ }^{24}$ epoxy-based sealers (AH Plus) penetrate deeper into the microirregularities because of its flowability and long polymerization time, which in turn enhances the mechanical interlocking between sealer and dentin. In addition, the cohesion between the sealer molecules increases the resistance

Table 1. Bond strength mean and standard deviation values (in $\mathrm{MPa}$ ) for the displacement of the filling material from the specimens in each group during the push-out test.

\begin{tabular}{|c|c|c|c|c|}
\hline \multirow{2}{*}{ Sealers } & & \multicolumn{3}{|c|}{ Filling technique } \\
\hline & & MicroSeal & Obtura II & Lateral compaction \\
\hline AH Plus & $4.34 \pm 1.80^{\mathrm{Aa}}$ & $5.16 \pm 2.22^{\mathrm{Aa}}$ & $4.56 \pm 1.48^{\mathrm{Aa}}$ & $3.29 \pm 0.98^{\mathrm{Ab}}$ \\
\hline Epiphany SE & $0.75 \pm 0.27^{B c}$ & $0.76 \pm 0.29^{B c}$ & $0.79 \pm 0.31^{\mathrm{Bc}}$ & $0.72 \pm 0.23^{B c}$ \\
\hline
\end{tabular}

Same lowercase letters indicate that there was no significant difference between rows $(p>0.05)$.

Same uppercase letters indicate that there was no significant difference between columns $(p>0.05)$. 
Table 2. Distribution of the mode of failure after the displacement of the filling material from the specimens in each group during the push-out test.

\begin{tabular}{lcccc}
\hline \multirow{2}{*}{ Filling technique/sealer } & \multicolumn{3}{c}{ Failure mode (\%) } \\
\cline { 3 - 5 } & & Adhesive & Mixed & Cohesive \\
\hline Obtura II & AH Plus & 23 & 60 & 17 \\
Obtura II & Epiphany SE & 93 & 7 & 0 \\
MicroSeal & AH Plus & 33 & 64 & 3 \\
MicroSeal & Epiphany SE & 87 & 13 & 0 \\
Lateral compaction & AH Plus & 43 & 57 & 0 \\
Lateral compaction & Epiphany SE & 77 & 23 & 0 \\
TOTAL & & 60 & 37 & 3 \\
\hline
\end{tabular}

to displacement of the material from dentin surfaces, which translates into greater adhesion. ${ }^{25}$ Based on previous studies, ${ }^{23,25,26}$ the outcome of Epiphany may be a result of incomplete sealer photoactivation caused by decreased light exposure in the deepest regions of the root canal or by oxygen inhibition. Consequently, there is a reduced degree of monomer conversion, resulting in lower bond strengths.

With respect to the filling techniques, the highest mean values were obtained when MicroSeal and Obtura II were used with AH Plus, and this group was different from the lateral-compaction groups $(\mathrm{p}<0.05)$, which showed statistical similarities with different types of sealers $(p>0.05)$. These results could be due to the improved flow of warm gutta-percha ${ }^{2,27}$ that, along with vertical compaction (performed to finish the filling procedure), resulted in high volume of a compact and homogeneous mass of gutta-percha and minimal volume of sealer. This is generally associated with higher material retention. ${ }^{28}$ Nevertheless, the cold lateral-compaction technique does not allow complete filling of the root canal system irregularities, resulting in absence of sealer and/or gutta-percha in some canal areas and reduced filling bond strength, ${ }^{10}$ as observed in the present study.

In addition, it is important to indicate that although both systems thermoplasticize the gutta-percha, MicroSeal has an intermediate procedure using a taper. 04 condenser at $5000 \mathrm{rpm}$. This is used to ensure a sufficient volume of gutta-percha in the canal and therefore higher bond strength may be expected with this technique. However, in the present study, no statistically significant differences were observed in the bond strength produced by MicroSeal and Obtura II techniques.

The analysis of failure type confirmed the bond strength results of the sealers and/or techniques used. Mixed failures were predominant with AH Plus, regardless of the technique used. In the Epiphany SE and lateral-compaction groups, the prevalence of adhesive failures can be explained by the weak adhesion of filling material to the root dentin. ${ }^{18,21}$

Here we also investigated the effect of root-thirds on sealer bond strength. According to Tao and Pashley, ${ }^{29}$ there are some structural differences in the root dentin, such as higher tubular density/diameter, and collagen fiber density in the cervical-third. Therefore, sealer bond strength must be higher in these parts of the root. However, it was observed that despite the structural differences, the sealer bond strength values between the root-thirds, for different filling techniques and/or sealer types, were statistically similar. These results could be due to the crown-down instrumentation performed before root filling. Because the cervical-third dentin presents higher tubular/collagen density, the instrumentation causes greater formation of smear layer in this area, which could negatively affect the filling material bond strength. ${ }^{29}$

Overall, in the present study, better results were observed with thermoplastic filling techniques, but the lateral-compaction bond strength values obtained were in accordance with previous studies which confirmed their clinical acceptability. ${ }^{5,10,30}$ Therefore, clinical implications of filling techniques and/or endodontic sealers should not be based on bond strength results alone; assessment of the sealing ability using different infiltration methods as well as 3-D micro-CT evaluations could provide different perspectives and demonstrate the actual effects of the materials/techniques used for endodontic treatment.

\section{Conclusion}

Within the limitations of the present study, it can be concluded that MicroSeal and Obtura II produce fillings with higher bond strengths within the root canal wall than lateral-compaction. AH Plus sealers produced higher bond strengths when compared with Epiphany SE, regardless of the filling technique used. 


\section{References}

1. Leonardo MR, Cervi DA, Tanomaru JMG, Silva LAB. Effect of different rotary instrumentation techniques and thermoplastic filling on apical sealing. J Appl Oral Sci. 2004;12(1):89-92. doi:10.1590/S1678-77572004000100016

2. Venturi M. Evaluation of canal filling after using two warm vertical gutta-percha compaction techniques in vivo: a preliminary study. Int Endod J. 2006;39(7):538-46. doi:10.1111/j.1365-2591.2006.01106.x

3. Ordinola-Zapata R, Bramante CM, Moraes IG, Bernardineli N, Garcia RB, Gutmann JL. Analysis of the gutta-percha filled area in C-shaped mandibular molars obtured with a modified MicroSeal techniques. Int Endod J. 2009;42(3):186-97. doi:10.1111/j.1365-2591.2008.01495.x

4. Ünal GÇ, Kaia BU, Taç AG, Keçece AD. A comparison of the efficacy of conventional and new retreatment instruments to remove gutta-percha in curved root canals: an ex vivo study. Int Endod J. 2009;42(4):344-50. doi:10.1111/j.1365-2591.2008.01518.x

5. De-Deus G, Reis C, Beznos D, Abranches AMG, Coutinho-Filho T, Paciornik S. Limited ability of three commonly used thermoplasticized gutta-percha techniques in filling oval-shaped canals. J Endod. 2008;34(11):1401-5. doi:10.1016/j.joen.2008.08.015

6. Gulsahi K, Cehreli ZC, Onay EO, Tasman-Dagli F, Ungor $\mathrm{M}$. Comparison of the area of resin-based sealer and voids in roots obturated with Resilon and gutta-percha. J Endod. 2007;33(11):1338-41. doi:10.1016/j.joen.2007.06.015

7. Davalou S, Gutmann JL, Nunn MH. Assessment of apical and coronal root canal seals using contemporary endodontic obturation and restorative materials and techniques. Int Endod J. 1999;32(5):388-96. doi:10.1046/j.1365-2591.1999.00246.x

8. Goldberg F, Artaza LP, Silvio A. Effectiveness of different obturation techniques in the filling of simulated lateral canals. J Endod. 2001;27(5):362-4. doi:10.1097/00004770-200105000-00015

9. Tagger M, Tagger E, Tjan AHL, Bakland LK. Measurement of adhesion of endodontic sealers to dentin. J Endod. 2002;28(5):351-54. doi:10.1097/00004770-200205000-00001

10. Brosco VH, Bernardineli N, Moraes IG. In vitro evaluation of the apical sealing of root canals obturated with different techniques. J Appl Oral Sci. 2003;11(3):181-85. doi:10.1590/S1678-77572003000300005

11. Karabucak B, Kim A, Chen V, Iqbal MK. The comparison of gutta-percha and resilon penetration into lateral canals with different thermoplastic delivery systems. J Endod. 2008;34(7):847-49. doi:10.1016/j.joen.2008.03.024

12. Cathro PR, Love RM. Comparison of Microseal and System B/Obtura II obturation techniques. Int Endod J. 2003;36(12):876-82. doi:10.1111/j.1365-2591.2003.00741.x

13. Maggiore F. MicroSeal systems and modified technique. Dent Clin North Am. 2004;48(1):217-64. doi:10.1016/j.cden.2003.11.005
14. Soo WK, Thong YL, Gutmann JL. A comparison of four gutta-percha filling techniques in simulated C-shaped canals. Int Endod J. 2015;48(8):736-46. doi:10.1111/iej.12371

15. Bradshaw GB, Hall A, Edmunds DH. The sealing ability of injection-moulded thermoplasticized gutta-percha. Int Endod J. 1989;22(1):17-20. doi:10.1111/j.1365-2591.1989.tb00500.x

16. Olson AK,HartwellGR, Weller RN. Evaluation of the controlled placement of injected thermoplasticized gutta-percha. J Endod. 1989;15(7):306-9. doi:10.1016/S0099-2399(89)80052-4

17. Gutmann JL, Saunders WP, Saunders EM, Nguyen L. An assessment of the plastic Thermafil obturation technique. Part 2. Material adaptation and sealability. Int Endod J. 1993;26(3):179-83. doi:10.1111/j.1365-2591.1993.tb00790.x

18. Gonçalves L, Silva-Sousa YT, Raucci Neto W, Teixeira CS, Sousa-Neto MD, Alfredo E. Effect of different irrigation protocols on the radicular dentin interface and bond strength with a metacrylate-based endodontic sealer. Microsc Res Tech. 2014;77(6):446-52. doi:10.1002/jemt.22365

19. Hörsted-Bindslev P, Andersen MA, Jensen MF, Nilsson JH, Wenzel A. Quality of molar root canal fillings performed with the lateral compaction and the single-cone technique. J Endod. 2007;33(4):468-71. doi:10.1016/j.joen.2006.12.016

20. Sousa-Neto MD, Coelho FI, Marchesan MA, Alfredo E, Silva-Sousa YTC. Ex vivo study of the adhesion of an epoxy-based sealer to human dentine submitted to irradiation with Er:YAG and Nd:YAG. Int Endod J. 2005;38(12):866-70. doi:10.1111/j.1365-2591.2005.01027.x

21. Rached-Junior FJ, Souza-Gabriel AE, Alfredo E, Miranda CE, Silva-Sousa YT, Sousa-Neto MD. Bond strength of Epiphany sealer prepared with resinous solvent. J Endod. 2009;35(2):251-5. doi:10.1016/j.joen.2008.10.027

22. Moinzadeh AT, Jongsma L, Wesselink PR. Considerations about the use of the push-out test in Endodontic research. Int Endod J. 2015;48(5):498-500. doi:10.1111/iej.12416

23. Shokouhinejad N1, Sharifian MR, Jafari M, Sabeti MA. Push-out bond strength of Resilon/Epiphany self-etch and gutta-percha/AH26 after different irrigation protocols. Oral Surg Oral Med Oral Pathol Oral Radiol Endod. 2010;110(5):e88-92. doi:10.1016/j.tripleo.2010.05.069

24. Carneiro SM, Sousa-Neto MD, Rached Junior FA, Miranda CE, Silva SR, Silva-Sousa YT. Push-out strength of root fillings with or without thermomechanical compaction. Int Endod J. 2012;45(9):821-8. doi:10.1111/j.1365-2591.2012.02039.x

25. Nunes VH, Silva RG, Alfredo E, Sousa-Neto MD, Silva-Sousa YT. Adhesion of Epiphany and AH Plus sealers to human root dentin treated with different solutions. Braz Dent J. 2008;19(1):46-50. doi:10.1590/S0103-64402008000100008

26. Alfredo E, Silva SR, Ozório JE, Sousa-Neto MD, Brugnera-Júnior A, Silva-Sousa YT. Bond strength of AH Plus and Epiphany sealers on root dentine irradiated with 980 nm diode laser. Int Endod J. 2008;41(9):733-40. doi:10.1111/j.1365-2591.2008.01418.x 
27. Wu M, van der Sluis LW, Wesselink PR. A preliminary study of the percentage of gutta-percha-filled area in the apical canal filled with vertically compacted warm gutta-percha. Int Endod J. 2002;35(6):527-35. doi:10.1046/j.1365-2591.2002.00522.x

28. Schilder H. Filling root canals in three dimensions. J Endod. 2006;32(4):281-90. doi:10.1016/j.joen.2006.02.007
29. Tao L, Pashley D. Shear bond strengths to dentin: effect of surface treatments, depth and position. Dent Mater. 1988;4(7):371-8. doi:10.1016/S0109-5641(88)80052-6

30. Dulac KA, Nielsen CJ, Tomazic TJ, Ferrillo Jr PJ, Hatton JF. Comparison of the obturation of lateral canals by six techniques. J Endod. 1999;25(5):376-80. doi:10.1016/S0099-2399(06)81175-1 